\title{
Stand-alone cage neck fusions: A long-term review
}

\author{
MM Maine MBChB(Medunsa) \\ Orthopaedic registrar, Department of Orthopaedics, University of Pretoria \\ I Zondagh MBChB(Pret), FCS Orth(SA), MMed(Orth) \\ Spinal consultant, Department of Orthopaedics, 1 Military Hospital, University of Pretoria
}

\author{
Corresponding author: \\ Dr MM Maine \\ Department of Orthopaedics \\ University of Pretoria \\ 1 Military Hospital \\ Private Bag x1026 \\ 0143 Thaba Tshwane
}

Email: motsapim@yahoo.com

Tel: (012) 3140044

Fax: 0866329182

\begin{abstract}
Background: Anterior cervical decompression and fusion (ACDF) is a well-known treatment for persistent cervical radiculopathy or myelopathy. Fusion is performed to stabilise the segment, maintain foraminal height, and maintain the normal sagittal profile. The stand-alone cage concept, initiated by Bagby, has been used in the human spine since 1988. There are some concerns with stand-alone cages regarding expulsion and migration of the cage.
\end{abstract}

Aim: To review the long-term outcome of stand-alone cage fusions done from 2000-2010 at 1 Military Hospital and describe our experience with this procedure.

Methods: A retrospective review of stand-alone cage neck fusion of 55 levels in 35 patients performed between January 2000 and December 2010 at 1 Military Hospital was done. Clinical notes and X-rays were reviewed. Fusion rate was assessed using standard X-rays with flexion/extension views.

Results: Seven patients (14\%) had a non-union, giving a fusion rate of $86 \%$. Five non-unions were painful. One patient had a revision for a painful non-union (NDI score: 35/50). One patient refused to have a revision at last visit despite having significant pain (NDI score: 27/50). One patient with a double level non-union has phaeochromocytoma with significant risk to revision and chose not to have the surgery (NDI score: $14 / 50$ ). Two patients are on the waiting list for a revision in the near future (NDI scores: 24/50 and 19/50). The two remaining patients with non-unions are asymptomatic (NDI scores: 0/50 and 7/50).

Conclusion: Stand-alone cage fusion is a safe and effective procedure providing a favourable clinical and radiological outcome. Good fusion rates can be obtained ( $86 \%$ in our study) with this method.

Key words: radiculopathy, myelopathy, anterior cervical discectomy and fusion, stand-alone cage fusion, fusion rate

\section{Introduction}

Anterior cervical decompression and fusion (ACDF) is a well-known treatment in the management of cervical degenerative disease causing persistent radiculopathy or myelopathy. Anterior surgery of the cervical disc with fusion using iliac crest autograft was introduced in the 1950s. ${ }^{1}$

After decompression, a fusion is performed to stabilise the segment, restore the height and recreate the normal cervical lordosis. Initially ACDF was performed using tricortical iliac bone graft with good fusion rates. 
The use of autologous bone graft gave rise to complications, especially acute and chronic pain at the donor site. Donor site morbidity favoured development of cage technology.

Anterior cervical plating was added to un-instrumented autograft fusion to prevent graft settling and collapse and to enhance a solid fusion. Plating however has its own challenges.

PEEK (polyether ether ketone) cervical synthetic cages have recently been used. PEEK has biomechanical properties similar to bone and is radiolucent allowing for post-operative radiographic fusion evaluation. The standalone cage concept was initiated by Bagby and has been used in the human spine since 1988. The rectangular cages used resemble the dimensions and anatomy of the disc space and vertebral end plates. There are concerns with stand-alone cage usage regarding expulsion and migration of the cage.

The purpose of the study is to review the long-term outcome of stand-alone cage fusions done from 2000 to 2010 at 1 Military Hospital and to describe our experience with the procedure.

The impact of the study is aimed to show that standalone cage fusion is a safe and effective procedure which provides a good clinical and radiological outcome.

\section{Methods}

A retrospective review was done on patients who underwent anterior cervical decompression and fusion using stand-alone cage at 1 Military Hospital between January 2000 and December 2010.

Patients were operated by a spinal team consisting of an orthopaedic surgeon and a neurosurgeon working together.

A standard right-sided Smith Robinson approach was used. After discectomy and decompression the end plates were prepared and the cage, packed with either autogenous bone, allograft bone or synthetic bone substitutes, was inserted. The cage size was determined by releasing distractor pins and assessing resistance to pull-out.

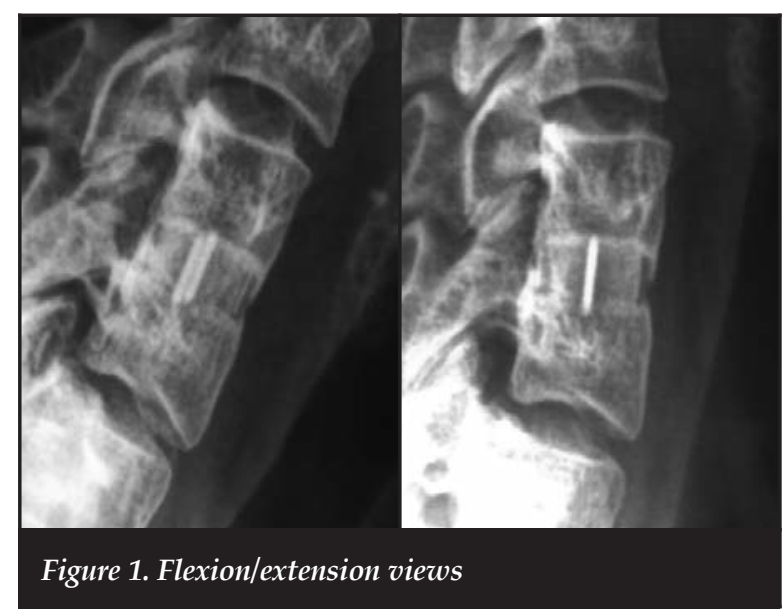

Post-operative immobilisation in a Philadelphia brace for 12 weeks was the standard of care.

Fusion rates were assessed using standard X-rays with flexion/extension views as shown in Figure 1. Trabecular continuity and bone bridging across the disc space, absence of motion with flexion/extension views and absence of a dark halo around the implant on AP and lateral views were assessed.

Patient clinical outcome was assessed using the Neck Disability Index score (NDI). The NDI was developed in 1989 by Vernon. ${ }^{2}$ Each of the ten items is scored from $0-5$. The maximum score is therefore 50 (see Appendix A). The obtained score can be multiplied by 2 to produce a percentage score. The scoring intervals for interpretation are as follows:

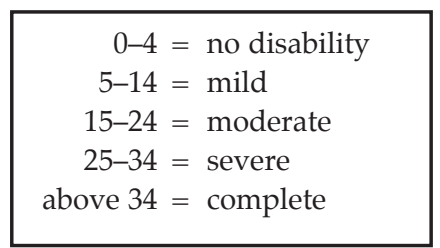

\section{Results}

Thirty-five patients were treated with stand-alone anterior cervical cages between January 2000 and December 2010 at 1 Military Hospital. Seventeen patients were male and 18 were female, with an average age of 58 years. Indications for surgery are shown in Figure 2. Follow-up was from 2 to 12 years with an average of 5 years. Most patients (22) underwent C5/C6 fusion, followed by C6/7 (11) as shown in Figure 3.

Eighteen patients had a 1-level fusion, 14 patients had a 2-level fusion and three patients had 3-level fusion (18 single level and 17 multilevel). Thus a total of 55 levels were fused. The average theatre time was 195 minutes.

The most frequently used cage height was $6 \mathrm{~mm}$ as depicted in Figure 4.

The graft material used was autograft in $82 \%$, allograft in $10 \%$ and synthetic bone substitute in $8 \%$ as illustrated in Figure 5.

Seven patients $(14 \%)$ had a non-union, giving a fusion rate of $86 \%$. Of the seven non-unions, there were no nonunion in the three level fusions. In the two-level fusion group there was one patient who had non-union at both operated levels. The remaining six non-union patients were all single-level surgery. Five non-unions were painful. One patient had a revision for a painful non-union (NDI score: 35/50), one patient refused to have a revision at last visit despite having significant pain (NDI score: $27 / 50$ ), one patient with a double-level non-union has phaeochromocytoma with significant risk to revision and chose not to have the surgery (NDI score: 14/50). Two patients are on the waiting list for a revision in the near future (NDI scores: 24/50 and 19/50). The two remaining patients are asymptomatic (NDI scores: $0 / 50$ and $7 / 50$ ). 


\section{Appendix A}

This questionnaire is designed to help us better understand how your neck pain affects your ability to manage everyday life activities. Please mark in each section the one box that applies to you. Although you may consider that two of the statements in any one section relate to you, please mark the box that most closely describes your presentday situation.

\section{SECTION 1 - PAIN INTENSITY}

I have no neck pain at the moment.

The pain is very mild at the moment.

The pain is moderate at the moment.

The pain is fairly severe at the moment.

$\square$ The pain is very severe at the moment.

The pain is the worst imaginable at the moment.

\section{SECTION 2 - PERSONAL CARE}

I can look after myself normally without causing extra neck pain.

I can look after myself normally, but it causes extra neck pain.

It is painful to look after myself, and I am slow and careful.

I need some help but manage most of my personal care.

I need help every day in most aspects of self-care.

I do not get dressed. I wash with difficulty and stay in bed.

\section{SECTION 3 - LIFTING}

I I can lift heavy weights without causing extra neck pain.

I can lift heavy weights, but it gives me extra neck pain.

Neck pain prevents me from lifting heavy weights of the floor but I can manage if items are conveniently positioned, i.e. on a table.

- Neck pain prevents me from lifting heavy weights, but I can manage light weights if they are conveniently positioned.

I can lift only very light weights.

I cannot lift or carry anything at all.

\section{SECTION 4 - READING}

I I can read as much as I want with no neck pain.

I can read as much as I want with slight neck pain.

I can read as much as I want with moderate neck pain.

I I can't read as much as I want because of moderate neck pain.

I can't read as much as I want because of severe neck pain.

I can't read at all.

\section{SECTION 5 - HEADACHES}

I have no headaches at all.

I have slight headaches that come infrequently.

I have moderate headaches that come infrequently.

I have moderate headaches that come frequently.

I have severe headaches that come frequently.

I have headaches almost all the time.

\section{SECTION 6 - CONCENTRATION}

I I can concentrate fully without difficulty.

I can concentrate fully with slight difficulty.

I have a fair degree of difficulty concentrating.

I have a lot of difficulty concentrating.

$\square$ I have a great deal of difficulty concentrating.

I I can't concentrate at all.

\section{SECTION 7 - WORK}

- I can do as much work as I want.

I I can only do my usual work, but no more.

I I can do most of my usual work, but no more.

I can't do my usual work.

I can hardly do any work at all.

I can't do any work at all.

\section{SECTION 8 - DRIVING}

$\square$ I can drive my car without neck pain.

I can drive my car with only slight neck pain.

I I can drive as long as I want with moderate neck pain.

I can't drive as long as I want because of moderate neck pain.

I can hardly drive at all because of severe neck pain.

I can't drive my car at all because of neck pain.

\section{SECTION 9 - SLEEPING}

I have no trouble sleeping.

My sleep is slightly disturbed for less than 1 hour.

- My sleep is mildly disturbed for up to 1-2 hours.

My sleep is moderately disturbed for up to 2-3 hours.

- My sleep is greatly disturbed for up to $3-5$ hours.

My sleep is completely disturbed for up to 5-7 hours.

\section{SECTION 10 - RECREATION}

I am able to engage in all my recreational activities with no neck pain at all.

I am able to engage in all my recreational activities with some neck pain.

- I am able to engage in most, but not all of my recreational activities because of pain in my neck.

$\square$ I am able to engage in a few of my recreational activities because of neck pain.

I can hardly do recreational activities due to neck pain. $\checkmark$ I can't do any recreational activities due to neck pain.

\section{PATIENT NAME}

DATE 


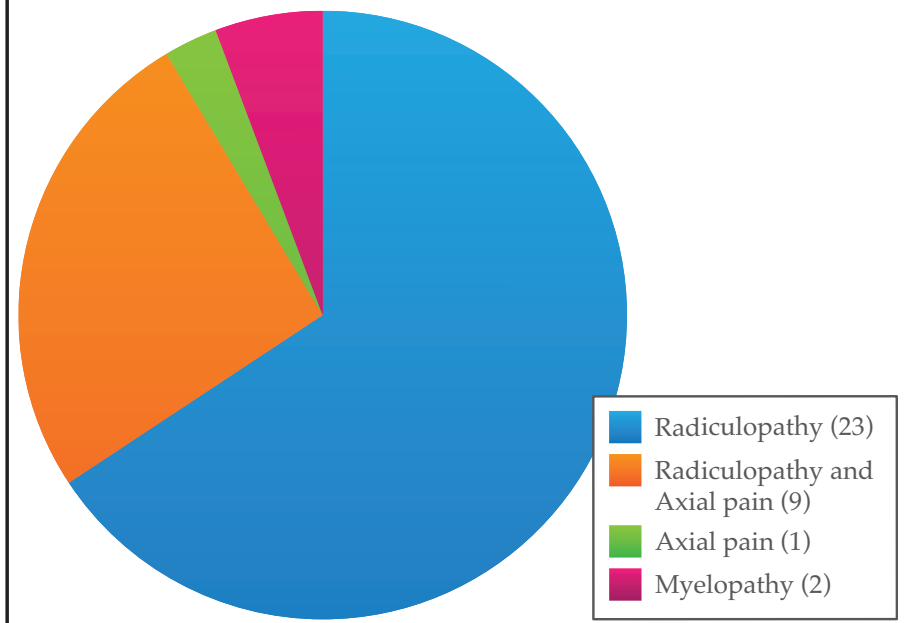

Figure 2. Indications for surgery

30

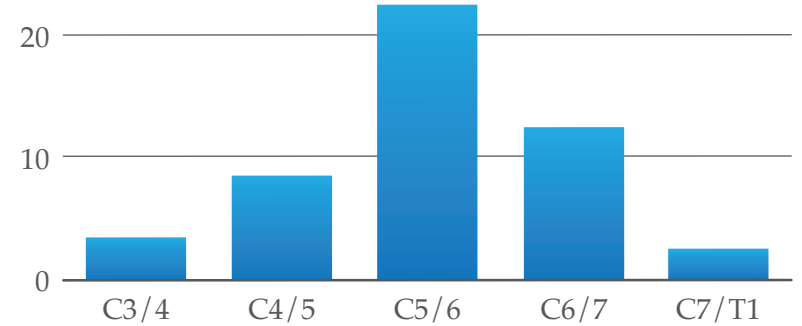

Figure 3. Levels operated

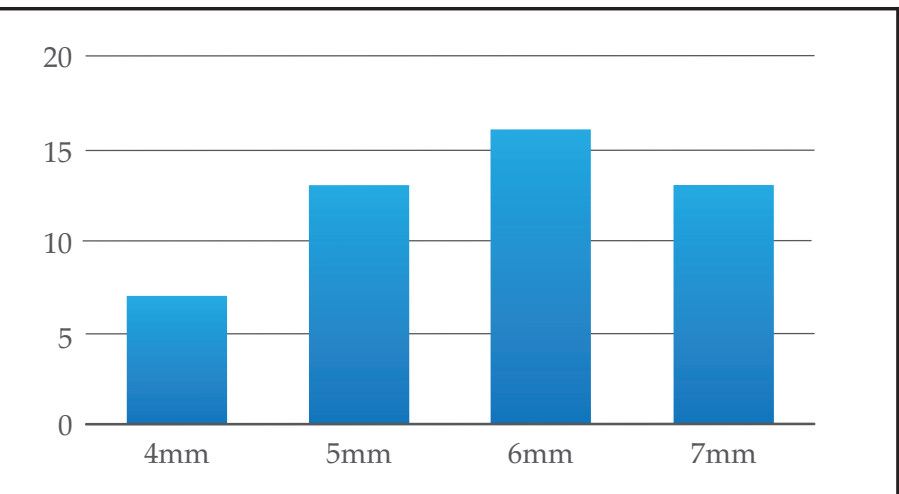

Figure 4. Cage size inserted

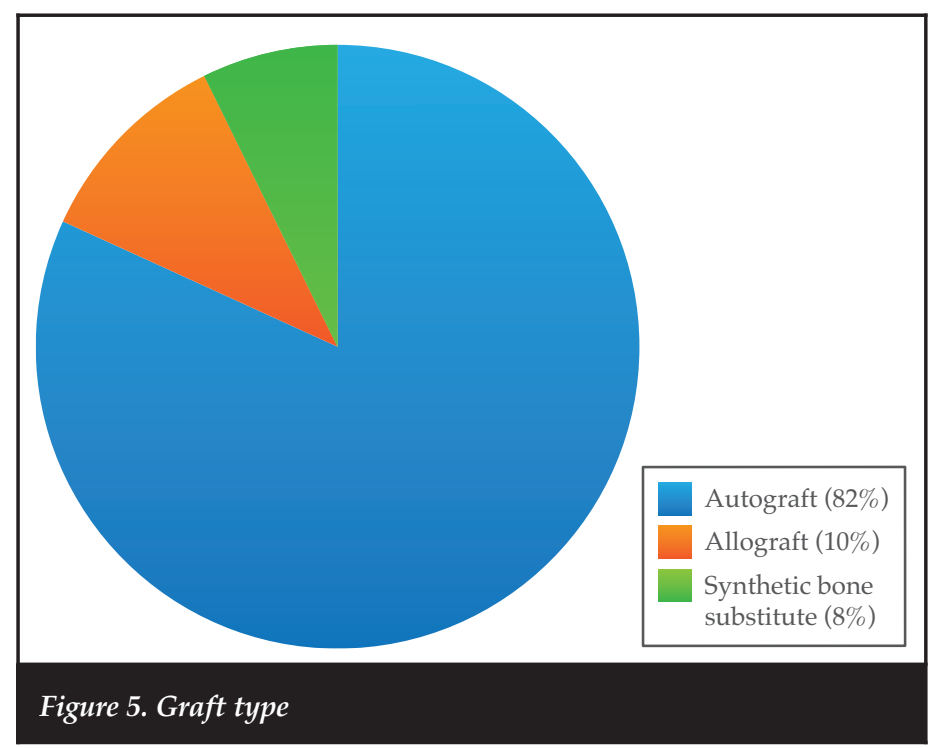

From the seven non-unions reported, with regard to bone graft material used, six out of seven non-unions were from autograft, and for the one, non-union synthetic graft was used.

In this study some complications were noted. One patient had a recurrent laryngeal nerve injury after a two-level fusion (C5-C7) and had a persistent speech problem at 9 years' follow-up. Another patient had an internal jugular vein injury which was ligated intra-operatively to control bleeding, theatre time was 390 minutes, and the patient was started on long-term anticoagulants. Another patient had a fracture of end plate at $\mathrm{C} 7$ which needed additional plate and screw fixation. Two cages were mal-positioned, one anterior and one lateral, but they did not cause any clinical problems. There were no infections, cerebrospinal fluid leaks or cage migrations in our study.

Fifteen of 35 patients (42\%) demonstrated radiological evidence of adjacent segment disease at 5-years' follow-up; however, only one patient required revision for adjacent segment disease (ASD).

\section{Discussion}

Degenerative disease of the cervical spine can result in significant radiculopathy, myelopathy or both. The anterior approach is the preferred method for decompression of the roots because of the easy patient positioning and surgical approach by blunt dissection through anatomical planes. With an anterior approach, however, interbody fusion is often required to maintain foraminal height and prevent localised kyphosis, especially with multiple-level surgery. Results of our study are comparable to other recent publications for stand-alone cage fusions. Marota et al. ${ }^{3}$ in their study of 132 patients showed an $87 \%$ fusion rate at 5-years' follow-up. Dunn et al. ${ }^{4}$ had a $92 \%$ fusion rate in 34 patients at 2-years' follow-up. Fraser et al. ${ }^{5}$ did a meta-analysis of fusion rates comparing different anterior fusion methods. 


\begin{abstract}
They found fusion rate to be $84.99 \%$ using anterior cervical decompression, $92.1 \%$ using anterior cervical decompression and fusion, and $97.1 \%$ using anterior cervical decompression and fusion with anterior plating. Plating is however more costly, requires longer operative times, and may be associated with problems such as breakage or dislocation of the screws and perforation of adjacent structures.

The use of interbody cages for anterior cervical fusion was introduced to prevent problems such as graft resorption and expulsion and therefore loss of alignment as seen with tricortical iliac bone graft. ${ }^{6}$

Cho et al. ${ }^{7}$ used cages to replace plate function in multilevel cervical fusion. They demonstrated that the PEEK cage results are statistically better than those of the plating group in total complications, $\mathrm{p}<0.05$. They also showed that PEEK cage without plating and autogenous iliac crest graft with plating are good methods for interbody fusion in multilevel cervical degenerative diseases.
\end{abstract}

We feel stand-alone cage fusion is a safe and effective procedure providing a good clinical and radiological outcome

Shousha et al. ${ }^{8}$ showed that stand-alone cage fusion is an acceptable line of treatment for four-level cervical disc disease, both clinically and radiologically, though the addition of posterior instrumentation yielded better radiological results; the difference, however, did not reach the statistical significance level.

Clinical follow-up was attempted but the clinical information/NDI scores were only obtained in 20 patients. There was a trend in our patients with a radiological nonunion to have a higher NDI score than those with radiological union.

Our ASD incidence is high compared to other literature $( \pm 25 \%)$, but our revision rate for ASD remains low despite the radiological picture. This brings us to question the clinical relevance of ASD.

McCormick et al. ${ }^{9}$ studied adjacent segment disease and demonstrated that adjacent segment disease is not clinically relevant. They also support the idea that ASD is the consequence of natural degeneration of the discs.

\section{Conclusion}

Almost $50 \%$ of our study group underwent multilevel fusion with one reported non-union. We feel stand-alone cage fusion is a safe and effective procedure providing a good clinical and radiological outcome for the management of cervical degenerative disease, even in multilevel disease.

Good fusion rates can be obtained $(86 \%)$ using this method.

The high incidence of adjacent segment disease seems not to be clinically relevant at long-term follow-up.

This study is the authentic work of the authors. No financial benefits were received from any commercial party for this study.

\section{References}

1. Cloward RB. The anterior approach for removal of ruptured cervical discs. J Neurosurg 1958;15:602-17.

2. Vernon H, Moirs S. The neck disability index: a study of reliability and validity. J Manip Physiol Ther 1991;14(7):40915 .

3. Marota N, Landi A, Tarantino R, Mancarella C, Ruggeri A, Delfini R. Five-year outcome of stand-alone fusion using carbon cages in cervical disc arthrodesis. Eur Spine J 2011;20(Suppl 1):S8-S12.

4. Dunn RN, Pretorius C. Cervical PEEK cage standalone fusions - the issue of subsidence. SA Orthopaedic Journal 2011;10(1):25-29.

5. Fraser JF, Härti R. Anterior approaches to fusion of the cervical spine: a meta-analysis of fusion rates. Neurosurg Spine 2007;6:298-303.

6. Bohlman HH, Emery SE, Goodfellow DB, Jones PK. Robinson anterior cervical discectomy and arthrodesis for cervical radiculopathy. Long-term follow-up of one hundred and twenty patients. I Bone Joint Surg (Am)1993;75:1298-1307.

7. Cho DY, Lee WY, Sheu PC. Treatment of multilevel cervical fusion with cages. Surg Neurol 2004;62:378-86.

8. Shousha M, Ezzati A, Boehm H. Four-level anterior cervical discectomies and cage-augmented fusion with and without fixation. Eur Spine J 2012;21:2512-19.

9. McCormick PC. The adjacent segment. J Neurosurg Spine 2007;6:1-4.

This article is also available online on the SAOA website (www.saoa.org.za) and the SciELO website (www.scielo.org.za). Follow the directions on the Contents page of this journal to access it. 